\title{
Augmented histamine test in the treatment of symptomatic hiatal hernia
}

\author{
W. SILBER \\ From the Oesophageal Clinic, Groote Schuur Hospital, Observatory, Cape Town, South Africa
}

SUMMARY The augmented histamine test was performed in 150 cases of oesophageal hiatal hernia with and without duodenal ulcers and the results have been analysed. There was no significant difference in the result compared with normals. In addition there is no correlation between the acid secretion and either symptoms or size of the hernia. The pathogenesis of heartburn is briefly discussed.

During the past two decades the importance of gastric reflux into the oesophagus in association with oesophageal hiatal hernia has been overstressed. It has generally been believed that this acid reflux was responsible for inevitable, serious, and irreversible oesophageal changes with resultant clinical symptoms. For this reason there have been and still are many who consider gastric reflux as an absolute indication for surgical treatment of oesophageal hiatal hernia. This has varied from partial gastrectomy to the balanced operation of vagotomy, drainage, and oesophageal hiatal repair (Berman and Berman, 1959; Herrington, 1962). It is the purpose of this paper to indicate that these views have been fallacious and that in fact the pathology and symptoms bear no relation to the height of the basal or maximal acid output.

\section{MATERIALS AND METHODS}

The augmented histamine test, as described by the Gastrointestinal Service of Groote Schuur Hospital (Marks, Bank, Moshal, and Louw, 1963) was performed in 150 unselected patients with symptomatic hiatal hernia. In this group there were 126 cases of sliding hiatal hernia, eight of composite hiatal hernia, and four of para-oesophageal hiatal hernia. Ninety-one were female and 47 were male patients. An additional 12 patients with sliding hiatal hernia had associated chronic duodenal ulcers. In this latter group were four females and eight males. The age range for the whole group was between 21 and 83 years.

These were compared with control and duodenal ulcer groups from the Gastrointestinal Service consisting of 26 females and 35 males in the former group, and 290 females and 1,159 males in the latter group (Bank, Marks, Louw, and Bock, 1967).

\section{RESULTS}

The basal gastric secretion in the hiatal hernia group is recorded in relation to those with and without heartburn (Fig. 1). A similar comparison is made with the maximal acid output. The hiatal hernias associated with duodenal ulcers were correlated in the same way (Fig. 2).

In the hiatal hernia group with heartburn the mean basal output was $2.0 \mathrm{~m}$-equiv/hr compared with $3.3 \mathrm{~m}$-equiv/hr in the group without heartburn and $3 \mathrm{~m}$-equiv/hr in the control group. There was no statistical significant difference in these figures.

The mean maximal acid output in the group with

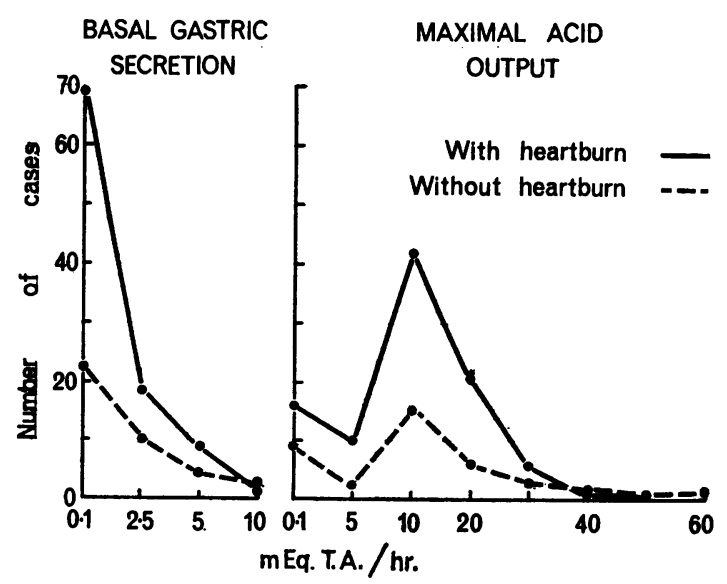

FIG. 1. Basal gastric secretion and maximal acid output in hiatal hernia in patients with and without heartburn. 


\section{BASAL GASTRIC SECRETION}

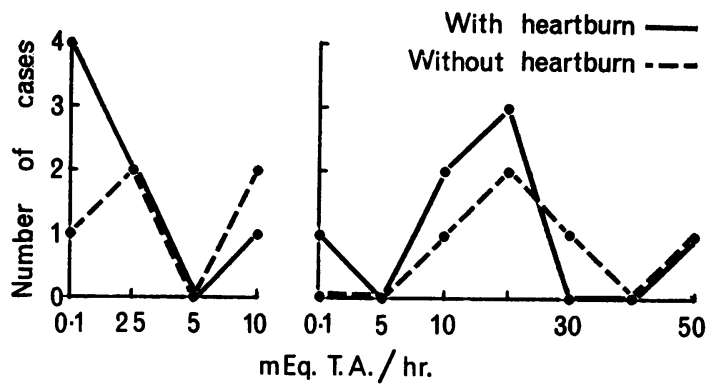

FIG. 2. Basal gastric secretion and maximal acid output in hiatal hernia and duodenal ulcer in patients with and without heartburn.

heartburn was $15.4 \mathrm{~m}$-equiv/hr compared with $18.3 \mathrm{~m}$-equiv $/ \mathrm{hr}$ in the group without heartburn. The mean in the control group was $18.9 \mathrm{~m}$-equiv/hr. Again there was no significant statistical difference.

In the group of patients with hiatal hernia and duodenal ulcer the mean basal secretion was $3.3 \mathrm{~m}$-equiv/ $\mathrm{hr}$ in the heartburn group and $6.2 \mathrm{~m}$ equiv/hr in those without heartburn. The mean in the duodenal ulcer group was $5 \cdot 2 \mathrm{~m}$-equiv/hr.

The mean maximal acid output was $21.8 \mathrm{~m}$-equiv $/ \mathrm{hr}$ in the heartburn group and $31.8 \mathrm{~m}$-equiv/ $\mathrm{hr}$ in the group without heartburn. This compared with the mean of $26.5 \mathrm{~m}$-equiv/ $\mathrm{hr}$ in the duodenal ulcer control group.

There was no significant difference statistically in the basal and maximal acid output and the control groups.

The symptoms, particularly heartburn, were not influenced by the height either of the basal or maximal acid output in any of the groups, even in those associated with duodenal ulcers where the output was higher. It is interesting to note that, although not statistically significant, the groups with heartburn are associated with an even lower basal and maximal acid output than those without heartburn.

\section{DISCUSSION}

Reflux oesophagitis-producing symptoms, the most important of which is heartburn, have always been considered to be caused by hyperacidity. Is this true? Casten and others (Casten, Bernhang, Nach, and Spinzia, 1963; Casten, 1964, 1967 ; Bernhang, Nach, and Casten, 1962; Castro 1967; Flood, Wells, and Baker, 1955; Herrington, 1962) were all of the opinion that sliding hiatal hernia was always associated with hyperacidity. In the groups of Casten and Bernhang the majority of patients with sliding hiatal hernia in whom there was hyperacidity had an associated duodenal ulcer. Casten et al (1963) considered that there was a direct correlation between the size of the hernia and the height of the acid; the larger the hernia the higher the acid. Giles, Clark, and Buchan (1968) found that perfusion of the oesophagus with acid produced an increase in the basal gastric secretion in symptomatic hiatal hernia. The supposition was that reflux of acid reflexly stimulated a further increase in the basal acid secretion.

As already discussed in the results the present analysis of the augmented histamine test does not confirm these findings. There was also no correlation between the acid secretion and the size of the hernia. Williams, Lawrie, and Forrest (1967) similarly found that there was no difference in the acid secretion between control and sliding hiatal hernia groups although those associated with duodenal ulcer had increased outputs. Reflux oesophagitis can also be present with normal acid output (Beaconsfield, 1953).

Heartburn is an oesophageal symptom which is usually associated with gastric acid reflux but the important factor is that it does not necessarily depend upon acid. I have patients who are hypersecretors, will reflux, and yet have no heartburn; patients with pernicious anaemia who have achlorhydria and present with heartburn, and others who have had total gastrectomies will reflux alkaline secretion which may produce the severest form of oesophagitis seen, possibly with resultant symptoms. It is not the nature of the reflux material that is important but the period during which it remains in the oesophagus and the ability of the oesophagus to clear the contents (Booth, Kemmerer, and Skinner, 1968) which may be important. My own view is that there is another very significant fact in the pathogenesis of heartburn and that is the sensitivity of the oesophageal mucosa (Silber, 1968). At least $40 \%$ of patients with symptomatic hiatal hernia will not demonstrate oesophagoscopically any oesophageal pathology to corroborate the diagnosis of peptic oesophagitis (Dagradi, Killian, and Schindler, 1958). Heartburn can also occur without reflux (Bockus, 1943; Nagler and Spiro, 1961).

The essential fact is that heartburn is due to an abnormal activity of the oesophageal musculature, usually in the form of a spasm which may be localized or diffuse. If not associated with reflux it may be dietetic or reflex as is seen with cholecystitis and spastic colon. The routine use of vagotomy in the treatment of hiatal hernia, other than in those cases associated with duodenal ulcers, is therefore felt to be an incorrect policy. 
Since completion of this analysis a further 100 cases of sliding hiatal hernia have been investigated in the same way with similar results.

My sincere thanks are due to the Gastrointestinal Service (Drs I. N. Marks and S. Bank) and their technical staff for enthusiastically and unhesitatingly undertaking all the augmented histamine tests which I requested; to Professor J. H. Louw, Professor of Surgery, University of Cape Town, for his constant encouragement and interest; to $\mathrm{Mr}$ Stephen Schach, BSc (Hon) of the Department of Applied Mathematics, University of Cape Town, for the statistical analysis and to Dr J. G. Burger, Superintendent, Groote Schuur Hospital, for permission to publish.

Please address requests for reprints to the Department of Surgery, Medical School, Observatory, Cape Town, South Africa.

\section{REFERENCES}

Bank, S., Marks, I. N., Louw, J. H., and Bock, O. A. A. (1967). The augmented histamine test. Recent Advances in Gastroenterology, 1, 399-403.

Beaconsfield, P. (1953). Reflux oesophagitis: Its diagnosis and treatment. Gastroenterology, 24, 369-377.

Berman, J. K., and Berman, E. J. (1959). Balanced operation for oesophagitis associated with oesophageal hiatal hernia. Arch. Surg., 78, 889-896.
Bernhang, A., Nach, R., and Casten, D. F. (1962). A study of nocturnal gastric acid secretion in patients with sliding esophageal hiatal hernia. Surg. Forum, 13, 250-251.

Bockus, H. L. (1943). Gastro-enterology, Vol. 1, p. 240. Saunders, Philadelphia.

Booth, D. J., Kemmerer, W. T., and Skinner, D. B. (1968). Acid clearing from the distal oesophagus. Arch. Surg., 96, 731-734.

Casten, D. F., Bernhang, A., Nach, R. J., and Spinzia, J. (1963). A physiological basis for the surgical treatment of sliding esophageal hiatal hernia. Surg. Gynac. Obstet., 117, 87-93.

Casten, D. F. (1964). Esophageal hiatal hernia and gastric acid secretion. Arch. Surg., 88, 255-259.

- (1967). Peptic esophagitis, hiatal hernia, and duodenal ulcer. Amer. J. Surg., 113, 638-641.

Castro, L. de P. (1967). Reflux esophagit is as the cause of heartburn in pregnancy. Amer. J. Obstet. Gynac., 98, 1-10.

Dagradi, A. E., Killian, R. N., and Schindler, R. (1958). Oesophageal hiatus hernia: an endoscopic study. Gastroenterology, 35, 54-61.

Flood, C. A., Wells, J., and Baker, D. (1955). Oesophageal reflux in simple heartburn. Ibid., 28, 28-33.

Giles, G. R., Clark, C. G., and Buchan, R. (1968). Effect of oesophageal perfusion with acid on basal gastric secretion. Gut, 9, 52-56.

Herrington, J. L. (1962). The treatment of oesophageal hiatal hernia. Arch Surg., 84, 379-389.

Marks, I. N., Bank, S., Moshal, M. G., and Louw, J. H. (1963). The augmented histamine test. S. Afr. J. Surg., 1, No. 2, 53-59.

Nagler, R., and Spiro, H. M. (1961). Heartburn in late pregnancy manometric studies of oesophageal motor function. J. clin. Invest., 40, 954-970.

Silber, W. (1968). Late results of the treatment of hiatal hernia. Amer. J. dig. Dis., 13, 252-259.

Williams, C. B., Lawrie, J. H., and Forrest, A. P. M. (1967). Acid secretion in symptomatic sliding hiatus hernia. Lancet, 1, 184-185. 